\title{
Teses em Mestrados Profissionais
}

\section{Carlos Osmar Bertero}

No momento os programas de pós-graduação em determinadas áreas estão lidando com a introdução dos mestrados profissionais. Embora mestrados profissionais sejam parte da tradição norte-americana de estudos pós-graduados, em nosso país se manteve, desde o início, a conhecida separação entre lato e stricto sensu, implicando mestrados e doutorados do lado acadêmico, e especialização do lado profissional.

Trata-se de uma aproximação do modelo que reconhece a existência de programas profissionais de pós-graduação. Assim, nos Estados Unidos de há muito encontramos os MBA (Master of Business Administration), o MPA (Master of Public Administration), o MLS (Master of Library Science) e até cursos profissionais oferecidos em nível de doutorado, que todavia mantêm a característica de doutorados profissionais e não se confundem com o doutorado científico ou Ph.D. É o caso dos doutores em medicina (MD) e advogados ou LLD. No Brasil manteve-se, até recentemente, uma separação rígida entre profissionais e acadêmicos; caso o desejassem, os primeiros deveriam realizar algum trabalho de pós-graduação lato sensu ou de especialização, que acabou caracterizado por menor prestígio científico e também social. Mestres e doutores continuaram sempre a ser secretos e intensos objetos de desejo, mesmo por parte de profissionais.

Atualmente começam a surgir no país mestrados profissionais em administração, com a sigla de MBA, letras que hoje despertam na comunidade de profissionais de administração, e até fora dela, tal encantamento, que já se anunciam MBAs até mesmo em contabilidade, direito e outras áreas, atestando que a ignorância, como a sabedoria, não conhece limites.

É conhecida de todos a lista de qualificações e de dúvidas que cercam a preparação de uma tese ou dissertação nos mestrados acadêmicos. Por isso não nos deteremos nesta matéria, embora reconheçamos que comportaria certamente ainda muitos debates. Vamo-nos limitar a apresentar algumas idéias sobre o que se deve esperar e solicitar de um candidato ao mestrado profissional. Primeiramente deve-se lembrar que os dois programas, o acadêmico e o profissional, têm objetivos essencialmente diversos. O primeiro volta-se à reprodução da instituição universitária. Mestres e doutores serão os futuros professores e pesquisadores e, portanto, responsáveis pela perpetuação da universidade no tempo. Podem ser vistos, assim, como graus confinados à própria universidade. Já o mestrado pro- 
fissional se abre para setores mais amplos da sociedade; no caso da administração, o seu objetivo é a formação de profissionais capazes de levar ao aprimoramento das práticas administrativas, que beneficiarão a sociedade em geral e as organizações em que irão atuar de maneira específica.

Enquanto o acadêmico não pode estar desvinculado da produção de conhecimento, que deve ser de preferência científico, o mestrado profissional se dirige à prática e ao aperfeiçoamento da administração, não necessariamente enquanto ciência ou acumulação de conhecimentos sistematizados. Não estamos aqui adentrando o complexo universo das relações entre teoria e prática, que constituem tópico fundamental para a área de administração. Simplesmente não o faremos, porque não consideramos seja este o momento e o espaço adequado para tratamento da questão, que mereceria outro momento.

Se nos quisermos aproximar de um formato que seria o de orientação e sugestão do que deveria ser uma tese de mestrado profissional em administração, forma de conciliar o MBA profissionalizante com o prestígio do grau de mestre brasileiro, privilégio do stricto sensu, vão aqui algumas idéias inventariadas por tópicos.

Primeiramente a questão dos objetivos: deve-se sempre levar em conta que a principal razão para que se escreva uma tese num mestrado profissionalizante é para que o mestrando obtenha o grau respectivo. Certamente a maioria preferiria, se forem bons mestrandos em programas profissionalizantes, dedicar o seu tempo à realização de outras coisas, como trabalhar numa organização e produzir. Se realmente tivessem que escrever alguma coisa, talvez optassem por um relatório voltado ao diagnóstico ou à solução de problemas organizacionais reais e concretos. Mas já que o grau tem de ser obtido e que para tanto se faz necessária uma tese, que ela seja próxima do universo de preocupações do mestrando. Seria, portanto, uma tese que poderia usar teorias, modelos ou conhecimentos de alguma forma sistematizados, que foram obtidos durante a realização do curso, mas que não deveriam necessariamente procurar construir ciência, pelo que não vejo necessidade de elaboração de hipóteses que viessem a ser comprovadas ou negadas. O trabalho de tese não deve ser percebido pelo candidato como desvio de seu universo de preocupações; deve nascer de um mundo de preocupações, típicas de profissional. Não vejo inconveniente que se aproxime do formato de um bom relatório de consultoria que se dedique a diagnosticar, analisar e propor soluções para um problema organizacional. Isto permite tanto uma tese com conteúdo e orientação funcional, como multifuncionalidade e posturas generalistas.

Outra questão sempre de alguma forma problemática para mestrandos e orientadores é a metodologia. A maioria dos textos e cursos de metodologia de pesquisa são marcados por conteúdo metodológico calcado na concepção de ciên- 
cia própria do positivismo lógico. É o modelo de ciência consolidado entre as ciências exatas, geociências e também, em boa medida, entre as biociências. Sua aplicação em pesquisas administrativas é pelo menos problemática. A não ser excepcionalmente, em administração, especialmente quando se trata de pesquisas que envolvem organizações enquanto unidades de análise, não se consegue obter a necessária e metodologicamente recomendável amostra que seja estatisticamente significativa. $\mathrm{Na}$ ausência de amostras que sirvam para justificar e embasar um bom tratamento estatístico, no contexto de um universo probabilístico, o que se acaba fazendo é aplicar pacotes quase sempre o SPSS (Statistical Program for the Social Sciences), cujos resultados estatísticos carecem de sentido, seja porque a amostra não é representativa do universo, seja porque a operacionalização de variáveis não foi adequadamente realizada. Conseqüentemente acabamos comparando variáveis incomparáveis, mas fazendo de conta que são comparáveis, prosseguindo e consolidando uma cadeia de equívocos.

A questão da metodologia deve estar atenta à multifuncionalidade da administração e ao caráter interdisciplinar e até mesmo sincrético, palavra nada recomendável em teoria da ciência, que a área como um todo possui. Cada área funcional acaba tendo diferenças enormes, que desencorajam a adoção de um único tipo de metodologia para o conjunto da administração. Desta forma podemos ter áreas, como produção e operações, que podem optar por uma metodologia que envolva modelagem matemática e que as distanciaria definitivamante de qualquer positivismo lógico, já que este modelo implica adoção, ab initio, de uma base empírica de dados e numa postura objetivista. A modelagem matemática nos leva ao plano do idealismo epistemológico e ao afastamento, por desnecessária, da realidade empírica. Modelagens matemáticas lidam sempre com entes de razão e não com dados de realidade empírica. Situações semelhantes podem ser encontradas na área financeira, particularmente com a aproximação que se vem dando nos últimos vinte anos entre finança empresarial (corporate finance) e o universo conceitual e analítico da economia. Há prêmios Nobel recentemente concedidos a obras que não são necessariamente econômicas, mas que se caracterizam pela sua aplicabilidade e pela sua capacidade de produzir instrumentos de análise ao gestor financeiro.

Se atentarmos para a área comercial (marketing e vendas), recursos humanos e algumas abordagens organizacionais, verificaremos que, dependendo do design da pesquisa, será adequada uma metodologia de tipo neopositivista, especialmente se for respaldada por fundamentações teóricas de tipo funcionalista ou marxista, que têm em comum o realismo e a objetividade do ponto de vista epistemológico.

Outra questão decisiva em metodologia para teses em administração é a importância e o espaço que se abrirão para as abordagens de tipo interpretacionista, que 
envolvem análise cultural a partir de uma perspectiva simbólico-interacionista, cuja realidade e significado se constroem socialmente. Não se pode recusar à etnometodologia um lugar de destaque, se as opções mencionadas forem adotadas pelo pesquisador. Mas, independentemente de tudo o que se afirmou, é um fato de nossa produção científica em administração no Brasil, que parte substancial dos trabalhos são estudos de caso, ou de um par de casos, que surgem simplesmente depois de uma discutível revisão teórica talvez, state of the art, e não necessariamente relacionada com ela; os casos não negam, tampouco confirmam o que as teorias apresentam, mas há o consenso de que aquilo é o que se pode produzir a partir das limitações que o pesquisador enfrenta, tanto de tempo como de recursos materiais para a pesquisa, como também considerando as limitações intelectuais do mestrando ou doutorando.

Do exposto, a conclusão que se pode tirar para teses de mestrado profissionalizante é que o estado da produção científica em administração em nosso país e a diversidade e a própria inconsistência científica da área de administração recomendam que se adote uma postura de tolerância e humildade. Não se leia aqui leniência em compactuar com maus trabalhos. É possível produzir ótimas e péssimas teses de mestrado profissionalizante, adotando qualquer das abordagens metodológicas disponíveis. O apelo à tolerância é para que se evite intransigência, arrogância e pretenso rigor e exatidão numa área onde tais atitudes não são cabíveis. A eliminação da leniência é feita em nome da exigência de qualidade, que deve estar presente em todas as teses, profissionalizantes ou acadêmicas.

A estruturação e organização de uma tese dependerá de fatores outros como a natureza do trabalho, a metodologia adotada e o design da pesquisa. Isto implica conceder ao pesquisador grande liberdade para que estruture o seu trabalho, o que signfica igualmente a adoção de boa margem de risco. Pouco mais se poderia dizer do que da necessidade de uma parte introdutória em que se coloque o problema ou o tema, se justifique a sua importância e depois se passe ao corpo do trabalho, onde se apresentem dados, se faça a análise de uma situação e se apresentem conclusões. Isto creio ser o máximo que se pode sugerir em termos de estruturação. Se nos ativermos ao que é possível e aceitável fazer num trabalho de tese de tipo profissionalizante, pode-se lembrar sempre a estrutura relativamente consagrada de um relatório de consultoria administrativa. Inicialmente tem-se a colocação do problema, como apresentada pelo cliente; isto é análogo à anamnese na clínica. São as queixas do paciente, o relato de seus sofrimentos e incluem normalmente as tentativas do próprio paciente em diagnosticar o mal ou males que o afligem. Depois disto tudo, há o corpo do trabalho, que é o esforço do consultor em tentar diagnosticar os males de seu paciente/cliente, fazendo uso dos 
dados que conseguiu levantar junto ao cliente, no ambiente de negócios em que o cliente atua e incluindo sua capacidade interpretativa e explicativa, fazendo uso de teorias e modelos e da sua própria experiência. Se isto tudo chegar a bom termo, é a hora da terapia, ou seja, ninguém busca o clínico, se não for para livrarse de seus males e sofrimentos. Nenhuma empresa contratará consultores, se não quiser ter os seus problemas solucionados. As recomendações do consultor costumam sempre ser esperadas com maior ansiedade do que suas interpretações, pois estas podem até mesmo desagradar ao cliente, a ponto de resistir em aceitá-las. Mas nunca se deixa de prestar atenção no que se prescreve como solução ou terapia para os problemas enfrentados.

Como se pode constatar, a estruturação de uma tese profissionalizante no formato de um relatório de consultoria não pode ser descartada como inadequada. Acredito que freqüentemente poderia ser até recomendável, pois estará mais próxima do universo do mestrando, que é um profissional, ou tornar-se-á em breve e, portanto, tem origem num mundo em que o mestrando vive ou viverá dentro em pouco.

Um aspecto muito importante de nossas teses de mestrado é a do espaço e da importância que se conferirão à revisão teórica, ou pomposamente ao estado-daarte". Não nos esqueçamos de que programas de mestrado acadêmico entre nós listam, em seus regimentos ou material de divulgação, que uma revisão da literatura ou apresentação do estado-da-arte sobre determinado tópico pode ser aceita como tese de mestrado. Se isto vale para a academia, e tem tanta importância, o que se pode dizer de uma tese num mestrado profissionalizante? Acredito que pode ser igualmente aceitável. Mas em geral nos sentimos um pouco decepcionados, quando algum orientado nos aparece querendo fazer apenas uma revisão da literatura. Gostaríamos de um pouco mais de ambição, ou que o tal estado-da-arte fosse pelo menos algo publicável como um capítulo dos Handbooks que nos chegaram ao longo de três décadas e pouco. O Handbook of Organizations, coordenado por James G. March nos anos sessenta, ou o recente Handbook of Organization Studies, coordenado por Stewart R. Clegg, Cynthia Hardy e Walter R. Nord. Fora isto, a decepção não é facilmente controlável e a auto-estima de orientador e orientado pode despencar.

$\mathrm{Na}$ tese de mestrado profissionalizante, acho fundamental que se inclua uma revisão da literatura. É na verdade uma boa e talvez única oportunidade para o mestrando mostrar que estudou detidamente alguma coisa, num curso onde não houve tempo, nem as condições estruturais e regimentais concedem muito tempo ao aprofundamento de qualquer assunto. Desta forma, a revisão da literatura deve ser vista como parte do processo de aprendizado em programas, cujos créditos obtidos em curso tendem a minguar. Especialmente com a oficialização dos dou- 
torados como os graus efetivamente acadêmicos e os mestrados como corredor de passagem e adicionalmente constrangido pela desejabilidade do doutorado direto, caso o candidato tenha maturidade e condições de saltar o mestrado. Portanto a revisão da literatura deve ser exigida com rigor, pois ela é parte importante do aprendizado em mestrados em que o total de créditos que se obtém em cursos anda ao redor de 30, ou seja, raramente mais de dez cursos.

Mas que a revisão da literatura não seja uma péssima, truncada e tediosa repetição do que pode ser mais bem entendido pela leitura direta dos autores e teorias revistos. A revisão da literatura tem de conter algo de crítico, tem de ser transmitida em linguagem e pulsação intelectual, que é a do mestrando, onde fique realmente demonstrado que a literatura revista foi absorvida e o que está sendo revisto é relevante para o tema da tese da qual é parte integrante. A revisão não deve repetir literalmente o que os autores revistos já escreveram, nem deve conter muitas citações. Cumpre seja feita numa linguagem concisa, e que seja do autor da tese, nunca dos autores revistos.

A escolha do tema é certamente a parte menos problemática de ser tratada em cotejo com uma tese de mestrado acadêmico. Já se disse no início desta colocação que o compromisso da tese acadêmica pode, mas não deve necessariamente ser como a produção científica. Já o mestrado profissionalizante se volta ao mundo da gestão, da prática ou da aplicabilidade. Isto é particularmente importante numa área, onde a aplicabilidade tem sido vista quase universalmente como sua predominante e talvez exclusiva característica. No mundo científico talvez nós, administradores, ou professores de administração, nos surpreendamos ao constatar que não há expectativas com relação a uma ciência da administração, mas há expectativas não só acadêmicas como sociais de que a administração forneça os instrumentos para uma boa prática. Não há dúvida, a maioria das pessoas, especialmente se não forem administradores, concordarão que se há algo que se faz mal é administrar as coisas. Todos querem estados, universidades, prefeituras, empresas, hospitais, polícias, escolas, etc, bem administrados; a maioria, creio, mostrar-se-á insatisfeita com o desempenho administrativo em quase todas essas organizações. Por isso não me parece caber dúvida de que a escolha de tema para uma tese de mestrado profissionalizante há de voltar-se à gestão e não à construção teórica, ou à comprovação ou refutação de hipóteses. Deixem esse mercado para os doutorandos e para os mestrados acadêmicos.

A escolha do tema pode ser feita mesmo em consonância com problemas existentes na organização à qual o mestrando esteja vinculado. O mestrado profissional entre nós tem mais probabilidade de se consolidar e atrair bons alunos, se houver o envolvimento das organizações que os empregam. Isto implica disponibilizar os alunos para que possam frequentar aulas e participar de ativida- 
des escolares importantes. Entre nós é raro que as pessoas poupem para pagar um mestrado profissional. O mais comum é fazê-lo enquanto empregado de uma organização. Isto é uma realidade nossa que não podemos deixar de reconhecer e que, portanto, justifica o envolvimento da organização com o mestrado profissionalizante de seus membros.

É sempre muito difícil falar ou sugerir algo sobre o que as outras pessoas deverão pesquisar e escrever. Mas podemos dizer que o tema deve ligar-se de preferência a problemas organizacionais concretos e envolver sempre uma perspectiva administrativista. Mestrados profissionais, embora não afastem e não devam deixar de abordar e ensinar teorias, são afinal programas comprometidos com a gestão de organizações.

Outra consideração que cumpre estar presente na escolha do tema é o que o mestrado significa para o mestrando em vias de se tornar mestre. A idéia de mestrado profissionalizante, especialmente as três miraculosas letras MBA, constituem artigo de importação. No seu país de origem, MBAs, às vezes freneticamente, vêm sendo procurados pelo fato de serem patamares decisivos nas carreiras das pessoas. O cotejo entre salários antes e depois de um MBA nos Estados Unidos é enorme, pelo menos para os graus conferidos pelas principais escolas de administração de negócios. No Brasil não creio o grau tenha essas mesmas características; os salários não estão inevitavelmente atrelados à posse de um MBA. $\mathrm{Na}$ verdade os empregadores entre nós não parecem ter noção muito clara do que seja um mestrado, pós-graduação lato sensu e mestrados profissionais. Cabe ainda às universidades um trabalho de informar ao mercado e aos potenciais compradores exatamente o que o produto é, e fornecer juntamente com a mercadoria um Manual do Usuário. Isto todavia não deve impedir que se atente para o fato de que as pessoas buscam programas de pós-graduação e especialmente mestrados profissionais, porque acreditam que tais graus, e a experiência universitária que obtém, os tornem mais capazes individualmente e dotados de um diferencial competitivo no mercado de trabalho, mercado este, repete-se à fadiga, torna-se cada dia mais difícil, cruel e competitivo. Na escolha do tema de uma tese de mestrado profissional, é portanto razoável que o candidato busque um tema que o ajude em sua carreira; isto não implica necessariamente conflitos com outras características que uma boa tese deve possuir.

A distinção entre teoria e prática entre academia e mercado de trabalho é fugaz e nublada em administração, área que todos reconhecem é hoje ainda mais uma prática do que ciência ou conjunto razoavelmente articulado de teorias. Mesmo assim, é bom advertir os professores que tenham tido sua experiência docente em stricto sensu e não se tenham dedicado muito à consultoria e ao treinamento de executivos, distanciando-se, portanto, do universo da administração enquanto 
gestão: caso esses professores passem a ensinar em mestrados profissionais, seria de todo conveniente que revissem suas exigências. No limite, creio que a persistência em querer impor a programas profissionalizantes critérios e formatos de tese que se costumam solicitar a candidatos a graus acadêmicos poderia levar a problemas sérios, incluindo a própria descaracterização dos mestrados profissionais. 